\title{
Specificity of affective and autonomic symptoms of depression in Parkinson's disease
}

\author{
Sergio E Starkstein, Thomas J Preziosi, Alfred W Forrester, Robert G Robinson
}

\begin{abstract}
Previous investigators have suggested that numerous symptoms used to diagnose depression, such as sleep or appetite disturbance, are non-specific in medically ill patients, and alternative diagnostic criteria should be developed. In the study this hypothesis was tested in Parkinson's disease (PD) by comparing patients with PD who reported a depressive mood with patients having $P D$ but without a depressive mood. Depressed patients showed a significantly higher frequency of both autonomic and affective symptoms of depression. Depressed patients with PD reported a significantly higher frequency of worrying, brooding, loss of interest, hopelessness, suicidal tendencies, social withdrawal, selfdepreciation, ideas of reference, anxiety symptoms, loss of appetite, initial and middle insomnia, and loss of libido when compared with non-depressed patients. No significant between-group differences, however, were observed in the frequency of anergia, motor retardation, and early morning awakening.
\end{abstract}

Depression is a frequent finding in patients with Parkinson's disease (PD).$^{1-2}$ In a recent cross-sectional study we found that $21 \%$ of a consecutive series of 105 patients with PD had major depression, while $20 \%$ had minor depression.

Since it has been demonstrated that depression in PD can be successfully treated with tricyclic drugs or ECT, ${ }^{4-5}$ it is of considerable importance to diagnose depression in this population. One of the major problems is that some of the central features of depression such as slowness, difficulty in concentrating, and loss of energy, may be frequent features of PD even in the absence of a depressive mood. Some investigators have suggested that among patients with brain disease, different diagnostic criteria should be developed to determine the existence of depression. ${ }^{6}$

In this study we examined the presence of depressive symptoms in a consecutive series of 105 outpatients with PD. Autonomic and affective symptoms of depression were measured in patients with and without a depressive mood to assess the specificity of particular depressive symptoms in the presence of depression in PD. Both groups were matched for age, Hoehn and Yahr stage of their $\mathrm{PD},{ }^{7}$ and duration of disease to control important confounding variables. To determine the extent of overlap between symptoms of PD and symptoms of depression the presence of autonomic and affective symptoms of depression were measured in non-depressed patients with PD and agematched non-depressed patients with an acute myocardial infarction (AMI).

\section{Material and methods \\ Study population}

From July 1986 to October 1987, a consecutive series of 105 patients with idiopathic Parkinson's disease who attended the neurology clinic at the Johns Hopkins Hospital were examined. Patients attending the clinic were seen for neurological evaluation or management of their disorder at regular follow up visits. Only one patient refused evaluation. Three patients who could not make their scheduled appointments because of poor health were interviewed in their homes.

Patients with AMI were screened during their hospital admission. They were randomly selected from admissions to the Cardiology Unit at the Johns Hopkins Hospital or the University of Maryland Hospital. A consecutive series of non-depressed patients with an AMI who were comparable in age to the non-depressed PD group were included.

\section{Neurological and clinical examination}

The neurological examination was carried out by one of us (TJP) who was blind to the neuropsychiatric data. The evaluation consisted of a comprehensive neurological examination and a rating scale for Parkinsonian symptoms. The rating scale quantitated the presence and severity of tremor, rigidity and akinesia (scores range from 0 to 3 ) in both the left and right limbs. On-off phenomena were rated as present (not necessarily at the time of the evaluation) or absent. Finally, activities of daily living were quantitated using the Northwestern Disability Scale (NWDS). ${ }^{8}$ Based on clinical findings, the stage of illness was determined using the Hoehn and Yahr stages.

Diagnosis of AMI was carried out by a cardiologist blind to the psychiatric data, and was based on clinical findings as well as on typical ECG and enzymatic changes.

\section{Psychiatric examination}

Except for diagnosis, the psychiatric examination was carried out blind to the neurological 
and cardiological examinations. After giving informed consent, patients were administered a series of standardised "quantitative" measures of mood, cognitive function, and social connectedness. Examinations were administered in a private room between 10 am and $2 \mathrm{pm}$ to minimise any possible effect of diurnal mood variation on their subjective report. The modified Present State Examination (PSE), ${ }^{9-10}$ a semistructured psychiatric interview that elicits symptoms related to depression and anxiety, was scored by the examiner (possible scores range from 0 to 144). The Hamilton Rating Scale for depression (HDS), ${ }^{11}$ a 17-item questionnaire (scores range from 0 to 52) measuring psychological and physiological symptoms of depression, was filled out by the interviewer.

Patients were included in the depressed group if they reported the presence of either moderate or severe depression (that is, sad mood) for more than $50 \%$ of the time during the past month. All other patients were considered to be non-depressed.

Since symptoms of PD (that is, anergia and motor retardation) may overlap with symptoms of depression, we matched depressed and non-depressed groups for stage and duration of their PD ( \pm 2 years). Similarly, since age and education may also influence the presence and likelihood of reporting depressive symptoms, depressed and non-depressed patients with PD were also matched for age ( \pm 2 years) and education ( \pm 2 years)

All patients with a depressive mood, who were eligible, were included in the study, and each of them was matched with the first nondepressed patient from a consecutive series that met the criteria mentioned above.

Based on the symptoms elicited using the structured psychiatric interview (PSE), a psychiatric diagnosis was made using DSMIII symptom criteria for major depression or minor (that is, dysthymic disorder excluding the two year duration criteria) depression. ${ }^{12}$ The method used to convert PSE symptoms to DSMIII major or minor depression diagnosis was discussed in a previous publication ${ }^{10}$ and is available upon request.

The Mini-Mental State Examination, ${ }^{13}$ an 11 item examination that has been found to be reliable in assessing a limited range of cognitive functions even in patients with brain disease, was also administered to each patient. Scores range from 0 to 30 and a score of 23 or below indicates significant cognitive impairment.

Social functioning was quantitated both by number of social connections using the Social Ties Checklist (maximum score of 10) and by personal satisfaction with social relationships using the Social Functioning Examination (scores range from 0 to 1000 , with higher scores indicating poorer social functioning). ${ }^{14}$

\section{Statistical analysis}

Statistical analysis was performed using means and SDs, two-way analysis of variance (ANOVA), and paired Student's $t$ test.
Frequency results were analysed using Chisquare tests with Yates' modification for expected cell sizes below 5. Non-parametric data analysis was performed using a Wilcoxon Paired test.

\section{Results}

Demographic findings

Demographic data are shown in table 1. No significant between-group differences emerged.

\section{Neurological findings}

There were no significant between-group differences in symptoms of PD, levodopa dosage, and frequency of "on-off" phenomena (table 2).

\section{Psychiatric findings}

After PSE items were clustered into autonomic and affective symptoms of depression ${ }^{15}$ (table 3), a 2-way ANOVA (factor 1: group (depressed versus non-depressed), factor 2 : PSE cluster (autonomic versus affective) showed a significant group effect $(F=138 \cdot 7, d f=1,28, p$ $<0.00001$ ), but no significant group $\times$ PSE cluster interaction $(F=0.01, p=N S)$ (the depressed group showed significantly higher scores for both, affective and autonomic clusters). On individual PSE item comparisons, the depressed group showed a significantly higher frequency of anxiety symptoms $\left(\chi^{2}=11 \cdot 0, \mathrm{df}=1, \mathrm{p}=0.00091\right)$, anxious foreboding $\left(\chi^{2}=17 \cdot 45, \mathrm{df}=1, \mathrm{p}=0.000029\right)$, loss of appetite $\left(\chi^{2}=3.7, \mathrm{df}=1, \mathrm{p}=0.05\right)$, initial insomnia $\left(\chi^{2}=10.3, \mathrm{df}=1, \mathrm{p}=0.0013\right)$, loss of libido $\left(\chi^{2}=10 \cdot 3, \mathrm{df}=1, \mathrm{p}=0.0013\right)$, middle insomnia $\left(\chi^{2}=16 \cdot 7, \mathrm{df}=1, \mathrm{p}=0.00078\right)$, worrying $\left(\chi^{2}=20.5, \mathrm{df}=1, \mathrm{p}=0.00001\right)$, brooding $\left(\chi^{2}=16 \cdot 2, \mathrm{df}=1, \mathrm{p}=0.000055\right)$, loss of interest $\left(\chi^{2}=11 \cdot 2, \mathrm{df}=1, \quad \mathrm{p}=0.00078\right)$, hopelessness $\left(\chi^{2}=22 \cdot 6, \mathrm{df}=1, \mathrm{p}=0.00001\right)$, suicidal ideation $\left(\chi^{2}=23 \cdot 7, \mathrm{df}=1, \mathrm{p}=0.00001\right)$, social withdrawal $\left(\chi^{2}=10.4, \mathrm{df}=1, \mathrm{p}=0.0012\right)$, selfdepreciation $\left(\chi^{2}=11 \cdot 8, \mathrm{df}=1, \mathrm{p}=0.00059\right)$, lack of self-confidence $\left(\chi^{2}=20.9, \mathrm{df}=1, \mathrm{p}=0.00001\right)$, and ideas of reference $\left(\chi^{2}=6 \cdot 1, \mathrm{df}=1\right.$, $\mathrm{p}=0.013)$. No significant differences were observed in anergia and motor retardation

Table 1 Demographic data

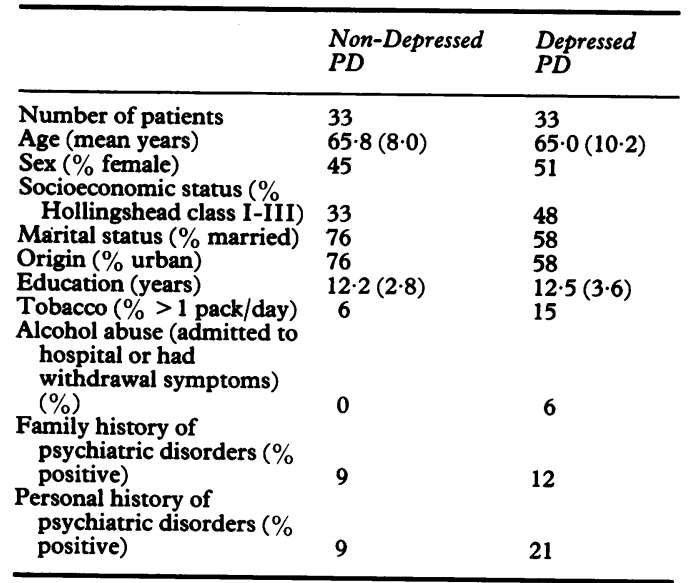

Figures in brackets indicate SDs. 
Table 2 Neurological findings

\begin{tabular}{lcc}
\hline & $\begin{array}{l}\text { Non-Depressed } \\
P D\end{array}$ & $\begin{array}{l}\text { Depressed } \\
P D\end{array}$ \\
\hline $\begin{array}{l}\text { Duration of the disease } \\
\text { (mean years) }\end{array}$ & $10 \cdot 0(8 \cdot 4)$ & $11 \cdot 2(6 \cdot 3)$ \\
$\begin{array}{l}\text { Levodopa + carbidopa } \\
\text { dosage (mean mg/d) }\end{array}$ & $877(878)$ & $909(470)$ \\
$\begin{array}{l}\text { Northwestern Disability } \\
\text { Scale Scores (mean) }\end{array}$ & $11 \cdot 8(9 \cdot 6)$ & $15 \cdot 4(10 \cdot 3)$ \\
$\begin{array}{l}\text { Tremor (mean score) } \\
\text { Rigidity (mean score) }\end{array}$ & $2 \cdot 39(2 \cdot 27)$ & $2 \cdot 51(2 \cdot 48)$ \\
$\begin{array}{l}\text { Akinesia (mean score) } \\
\text { On-off phenomena (\% }\end{array}$ & $3 \cdot 60(1 \cdot 96)$ & $3.42(1 \cdot 54)$ \\
positive) & 33 & $3.69(1.96)$ \\
\hline
\end{tabular}

Figures in brackets indicate SDs.

Table 3 Symptoms of depression

\begin{tabular}{|c|c|c|}
\hline & $\begin{array}{l}\text { Non-Depressed } \\
P D\end{array}$ & $\begin{array}{l}\text { Depressed } \\
P D\end{array}$ \\
\hline $\begin{array}{l}\text { Affective symptoms } \\
\text { Worrying }{ }^{\star \star} \\
\text { Brooding } \\
\text { Loss of interest }^{\star \star} \\
\text { Hopelessness } \\
\text { Suicidal tendencies } \\
\text { Social withdrawal } \\
\text { Self-depreciation } \\
\text { Ideas of reference }\end{array}$ & $\begin{array}{l}33(11) \\
15(5) \\
15(5) \\
12(4) \\
0 \\
15(5) \\
0 \\
36(12)\end{array}$ & $\begin{array}{l}88(29) \\
64(21) \\
55(18) \\
70(23) \\
52(17) \\
52(17) \\
30(10) \\
67(22)\end{array}$ \\
\hline $\begin{array}{l}\text { Presence of } \\
0 \text { or } 1 \text { symptom } \\
2 \text { symptoms } \\
3 \text { or more symptoms }\end{array}$ & $\begin{array}{l}55(18) \\
24(8) \\
21(7)\end{array}$ & $\begin{array}{c}.0 \\
0 \\
100(3)\end{array}$ \\
\hline $\begin{array}{l}\text { Autonomic symptoms } \\
\text { Autonomic anxiety } \\
\text { Loss of appetite } \\
\text { Initial insomnia } \\
\text { Middle insomnia }^{\star \star} \\
\text { Early morning awakening } \\
\text { Anergia and retardation } \\
\text { Loss of libido }\end{array}$ & $\begin{array}{l}9(3) \\
3(1) \\
24(8) \\
12(4) \\
24(8) \\
58(19) \\
27(9)\end{array}$ & $\begin{array}{l}45(15) \\
27(9) \\
45(15) \\
61(20) \\
45(15) \\
76(25) \\
67(22)\end{array}$ \\
\hline $\begin{array}{l}\text { 'resence of } \\
0 \text { or } 1 \text { symptom } \\
2 \text { symptoms } \\
3 \text { or more symptoms }\end{array}$ & $\begin{array}{l}45(15) \\
30(10) \\
24(7)\end{array}$ & $\begin{array}{c}3(1) \\
9(3) \\
88(29)\end{array}$ \\
\hline
\end{tabular}

${ }^{\star} \mathrm{p}<0.05,{ }^{\star \star} \mathrm{p}<0.001$

Numbers of patients are shown in brackets. Frequencies are expressed as a percentage of the 33 patients in each group.

$\left(\chi^{2}=2 \cdot 45, \mathrm{df}=1, \mathrm{p}=0 \cdot 11\right)$ or early morning awakening $\left(\chi^{2}=3 \cdot 26, \mathrm{df}=1, \mathrm{p}=0.075\right)$ (table 3).

Twenty two patients $(67 \%)$ in the depressed group met diagnostic criteria for major depression, while the remaining 11 patients (33\%) met diagnostic criteria for minor depression. While five patients $(15 \%)$ from the nondepressed group would have met diagnostic criteria for minor depression if they had reported experiencing a depressive mood, none would have met the diagnostic criteria for major depression. The sensitivity and specificity of autonomic and affective symptoms for overall (major and minor) depression, and for major depression only, is shown in table 4.

The depressed group had significantly higher mean depression scores when compared with the non-depressed group (table 5 ). The
Table 5 Scores of depression, cognitive impairment, and social functioning

\begin{tabular}{|c|c|c|}
\hline & $\begin{array}{l}\text { Non-depressed } \\
P D\end{array}$ & $\begin{array}{l}\text { Depressed } \\
P D\end{array}$ \\
\hline \multirow{3}{*}{$\begin{array}{l}\text { Present State Exam (mean) } \\
\text { Hamilton Depr. Scale } \\
\text { (mean) } \\
\text { Mini-Mental State (mean) } \\
\text { Social Ties (mean) } \\
\text { Social Functioning Exam } \\
\text { (mean) } \\
\text { Major Depression (\%) } \\
\text { Minor Depression (\%) }\end{array}$} & $3.4(2 \cdot 2)$ & $18 \cdot 2(17 \cdot 4)$ \\
\hline & $\begin{array}{r}2.5(1.9) \\
27.0(4.3) \\
2.7(1.6)\end{array}$ & $\begin{array}{r}12.6(5.6) \\
26.0(4.9) \\
3.6(1.4)\end{array}$ \\
\hline & $\begin{array}{c}108(165) \\
0 \\
0\end{array}$ & $\begin{array}{c}133(196) \\
67 \\
33\end{array}$ \\
\hline
\end{tabular}

${ }^{\star} \mathrm{t}=11,1, \mathrm{df}=1,64, \mathrm{p}<0.00001$

$\star \star t=9.91, \mathrm{df}=1,64, \mathrm{p}<0.0000$

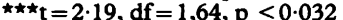

Numbers in brackets indicate SDs.

depressed group had a somewhat lower MMSE scores, and differences did not reach statistical significance (table 5). Finally, while betweengroup differences in social functioning were not statistically significant, depressed patients had significantly fewer social ties (table 5).

One third of our patients had a history of motor fluctuations but none of them was examined during the "off" period. Moreover, even when patients with motor fluctuations were excluded from the analysis, there was still a significant group effect $(\mathrm{F}=113 \cdot 1, \mathrm{df}=1,84$, p $<0.0001)$, but no significant group $\times$ PSE cluster interaction $(\mathrm{F}=0.01, \mathrm{df}=1,84, \mathrm{p}=$ NS) (the depressed group showed significantly higher scores for both, affective and autonomic clusters).

Comparison between non-depressed PD and nondepressed AMI groups

No significant between-group differences were observed on main demographic variables [age: PD, mean years (SD): 64.0 (7.4), AMI: 63.5 (6.6); sex: PD (\% females): $38 \%$, AMI: $23 \%$; education, mean years (SD): PD: 12.4 (3.0), AMI: 11.5 (4.6); MMSE, mean scores (SD): PD: $27 \cdot 6$ (3.9), AMI: $27 \cdot 1$ (2.5)].

A two-way ANOVA (factor 1: group (PD versus AMI); factor 2: PSE cluster (autonomic versus affective)), failed to show a significant group effect $(\mathrm{F}=0 \cdot 19, \mathrm{df}=1,100, \mathrm{p}>0 \cdot 10)$ or a significant group $\mathrm{X}$ cluster interaction $(\mathrm{F}=0.47, \mathrm{df}=1.100, \mathrm{p}>0 \cdot 10)$. The nondepressed PD patients were no more likely to have either autonomic or affective symptoms of depression than patients with an acute myocardial infarction.

\section{Discussion}

This study examined the specificity of depressive symptoms in patients with PD. We found that depressed patients showed significantly higher frequencies of both autonomic and affective symptoms of depression when com-

Table 4 Sensitivity and specificity of autonomic and affective symptoms

\begin{tabular}{|c|c|c|c|c|}
\hline & \multicolumn{2}{|c|}{ Major and minor depression } & \multicolumn{2}{|c|}{ Major depression } \\
\hline & Sensitivity & Specificity & Sensitivity & Specificity \\
\hline $\begin{array}{l}3 \text { or more autonomic symptoms } \\
3 \text { or more affective symptoms } \\
3 \text { or more affective and autonomic symptoms }\end{array}$ & $\begin{array}{r}91 \% \\
100 \% \\
88 \%\end{array}$ & $\begin{array}{l}\mathbf{7 6} \% \\
\mathbf{7 9} \% \\
\mathbf{9 7} \%\end{array}$ & $\begin{array}{r}96 \% \\
100 \% \\
96 \%\end{array}$ & $\begin{array}{r}86 \% \\
77 \% \\
100 \%\end{array}$ \\
\hline
\end{tabular}


pared with non-depressed patients matched for age, education, and duration and stage of illness. Analysis of individual symptoms of depression showed that, except for anergia, motor retardation, and early morning awakening, all depressive symptoms differed significantly between depressed and non-depressed patients.

When non-depressed PD patients were compared with non-depressed patients with an AMI, no significant between-group differences in terms of autonomic or affective symptoms of depression were observed. This suggests that PD in the absence of depression, compared with another medical disorder or a group of normal controls, ${ }^{16}$ does not contribute significantly to the presence of depressive symptoms.

One of the greatest difficulties in making a diagnosis of depression in patients with $P D$ is that the central features of PD, such as bradykinesia and motor retardation, are similar to those of a retarded endogenous depression. Patients with $\mathrm{PD}$ as well as patients with functional (that is, no known brain injury) depression may show a blank facial expression, apathy, a stooped posture, as well as sleeping problems. This overlap may confuse studies of depression in PD, and some studies have dealt with this problem by dropping from the depression scales those items that were considered to be related to PD rather than to depression. ${ }^{17}$ The validity of this procedure has never been established and this study is the first to examine the specificity of affective and autonomic symptoms for depression in patients with PD.

We found that while the presence of three or more autonomic or affective symptoms of depression had a high sensitivity for the detection of depression $(91 \%$ and $100 \%$, respectively), the specificity was not so good ( $76 \%$ and $79 \%$, respectively). Thus, there is a group of patients with PD that show some symptoms of depression in the absence of a depressive mood. This agrees with our finding that $15 \%$ of the non-depressed patients would have met diagnostic criteria for a minor depression. None of the non-depressed patients, however, would have met the diagnostic criteria for a major depression, and the presence of three or more affective and autonomic symptoms of depression classified patients with a high sensitivity and specificity $(88 \%$ and $97 \%$, respectively, for major plus minor depressed patients, and $96 \%$ and $100 \%$, respectively, for major depressed patients).

Symptoms that were not significantly different between depressed and non-depressed groups were anergia, motor retardation, and early morning awakening. These findings are not surprising, since motor retardation (related to bradykinesia and rigidity), is one of the most conspicuous symptoms of PD. ${ }^{18}$ Early morning awakening is also a frequent complaint of patients with $P D$, and is the result of either "wearing-off" phenomena, morning dystonic movements (which are sometimes painful), or both. ${ }^{18-19}$ Thus, anergia, motor retardation, and early morning awakening should not be
Table 6 Diagnostic criteria for depression

Criteria for Major Depression (adapted from DSM-III)"

A Dysphoric mood

B At least four of the following symptoms:

(1) Poor appetite or significant weight loss

(2) Insomnia

(3) Loss of interest or pleasure in usual activities, or decrease in sexual drive

(4) Feelings of worthlessness, self-reproach, or excessive or inappropriate guilt

(5) Complaints or evidence of diminished ability to think or concentrate, such as slowed thinking, or indecisiveness

6) Recurrent thoughts of death, suicidal tendencies, wishes to be dead, or suicide attempt

Criteria for Minor Depression (Dysthymia) (adapted from DSM-III) $)^{11}$

A Dysphoric mood

B Presence of at least three of the following symptoms:

(1) Insomnia

(2) Feelings of inadequacy, loss of self-esteem, or self-depreciation

(3) Decreased effectiveness or productivity

(4) Decreased attention, concentration, or ability to think clearly

(5) Social withdrawal

(6) Loss of interest in or enjoyment of pleasurable Loss of in

(7) Inability to respond with apparent pleasure to praise or rewards

(8) Pessimistic attitude toward the future, brooding about past events, or feeling sorry for self

(9) Tearfulness or crying

10) Recurrent thoughts of death or suicide

included in the criteria used to diagnose depression in PD, and should not be rated on the depression scales used in this population. Based on the present findings, we suggest that the diagnostic criteria shown in table 6 be used for the diagnosis of major and minor depression in patients with $P D$.

These findings do not rule out the possibility that some symptoms besides anergia and early awakening may be "non specific" for depression in a medically ill population. This question will need to be studied with other groups of patients with PD as well as in patients with other medical illnesses. We found similar results in a recent study on the specificity and sensitivity of affective and autonomic symptoms of depression in patients with acute stroke lesions. ${ }^{20}$ That is, patients with acute stroke lesions who reported a depressive mood had a significantly higher frequency of autonomic and affective symptoms of depression than patients with acute stroke lesions without a depressive mood. It should also be stated that among our non-depressed patients with PD, autonomic symptoms were not rampant. They did not elevate the depression scores of nondepressed patients with PD into the depressed range (that is, mean Hamilton Depression Scale score of 2.5 among the non-depressed) and did not create "cases" that may be "noncases" (that is, none of the non-depressed patients would have met symptom criteria for major depression in the presence of a depressed mood).

In conclusion, we have empirically examined the sensitivity and specificity of both autonomic and affective symptoms for depressive disorders in patients with PD. From a practical standpoint, the exclusion of anergia, motor retardation, and early morning awakening from the diagnostic criteria for depression in patients with PD may allow a better identification of patients with depression who may benefit from 
adequate treatment. ${ }^{4-5}$ From a research standpoint, these revised diagnostic criteria may provide more homogeneous populations of depressed and non-depressed patients for studying important interactions between depression, motor symptoms of PD, and cognitive impairment.

This work was supported in part by the following National Institutes of Health grants: Research Scientist Award MH00163 (RGR), MH-40355, NS-15178, and NS-15080. It was also supported by a grant from the University of Buenos Aires (SES), and by a National Alliance for Research in Schizophrenia and Depression Award (SES).

1 Mayeux R, Stern Y, Rosen J, Leventhal J. Depression, intellectual impairment, and Parkinson's disease. Neurology 1981;31:645-50.

2 Gotham AM, Brown RG, Marsden CD. Depression in Parkinson's disease: a quantitative and qualitative analysis. J Neurol Neurosurg Psychiatry 1986;49:381-9.

3 Starkstein SE, Preziosi TS, Bolduc PL, Robinson RG. Depression in Parkinson's disease. J Nerv Ment Dis 1990;178:27-34.

4 Anderson J, Aabro E, Gutmann N, Hjelmsted A, Pederson HE. Antidepressive treatment in Parkinson's disease: A controlled trial of the effect of nortryptiline in patients with Parkinson's disease treated with 1-dopa. Acta Neurol Scand 1980;62:210-19.

5 Yudofsky SC. Parkinson's disease, depression and electroconvulsive therapy: A clinical and neurobiologic synthesis. Compr Psychiatry 1979;20:579-81.

6 Ross ED, Rush AJ. Diagnosis and neuroanatomical correlates of depression in brain damaged patients. Arch Gen Psychiatry 1981;38:1344-54.
7 Hoehn MM, Yahr MD. Parkinsonism: onset, progression and mortality. Neurology 1967;17:427-42.

8 Canter GJ, de La Torre R, Mier M. A method for evaluating disability in patients with Parkinson's disease. J Nerv Ment Dis 1961;133:143-7.

9 Wing JK, Cooper JE, Sartorius N. Measurement and classification of psychiatric symptoms. Cambridge: Cambridge University Press, 1974.

10 Robinson RG, Kubos KL, Starr LB, Rao K, Price TR. Mood changes in stroke patients: relationship to lesion location. Compr Psychiatry 1983;24:555-66.

11 Hamilton MA. A rating scale for depression. J Neurol Neurosurg Psychiatry 1960;23:56-62.

12 American Psychiatric Association. Diagnostic and statistical manual of mental disorders (DSM-III). Third ed. Washington, DC: American Psychiatric Association, 1980.

13 Folstein MF, Folstein SE, McHugh PR. 'Mini-Mental State': A practical method for grading the cognitive state of patients for the clinician. J Psych Res 1975;12:189-98.

14 Starr LB, Robinson RG, Price TR. Reliability, validity, and clinical utility of the social functioning exam in the assessment of stroke patients. Exp Aging Res 1983;9: $101-6$.

15 Davidson J, Turnbull CG. Diagnostic significance of vegetative symptoms in depression. Brit J Psychiatry 1986;148:442-6.

16 Levin BE, Llabre MM, Weiner WJ. Parkinson's disease and depression: psychometric properties of the Beck Depresdepression: psychometric properties of the Beck Depres-
sion Inventory. J Neurol Neurosurg Psychiatry sion Inventory.

17 Robins AH. Depression in patients with Parkinsonism. Brit J Psychiatry 1976;128:141-5.

18 Goetz CG, Tanner CM, Levy M, Wilson RS, Garron DC. Pain in idiopathic Parkinson's disease. Movement Disorders 1986;1:45-9.

19 Lees AJ, Blackburn NA, Campbell VL. The nighttime problems of Parkinson's disease. Clin Neuropharmacol 1988;11:512-19.

20 Fedoroff JP, Starkstein SE, Parikh RM, Price TR, Robinson RG. Are depressive symptoms non-specific in patients with acute stroke? Am J Psychiat 1990 (in press). 